\title{
Geodynamics, tomographic images and seismicity of the Vrancea region (SE-Carpathians, Romania)
}

\author{
F. Wenzel ${ }^{1}$, B. Sperner ${ }^{1}$, F. Lorenz ${ }^{1}$, and V. Mocanu ${ }^{2}$ \\ ${ }^{1}$ Geophysical Institute, University of Karlsruhe, Hertzstr. 16, 76187 Karlsruhe, Germany \\ ${ }^{2}$ Geophysical Institute, University of Bucharest, Str. Traian Vuia 6, 70139 Bucharest, Romania
}

Received: 2 May 2000 - Accepted: 27 March 2002

\begin{abstract}
A joint interpretation of geological evidence, new seismic tomographic inversions, and seismicity observations suggest that the SE-Carpathians are the site of an on-going plate break-off process after subduction and collision ceased 10 million years ago. A high-velocity body clearly visible between 70 and $350 \mathrm{~km}$ depth hosts in its upper part $(<200 \mathrm{~km})$ the intermediate-depth strong seismicity. Its deeper aseismic part provides the gravitational pull to generate the necessary high-shear stresses.
\end{abstract}

\section{Introduction}

The Southeastern Carpathians are the site of a very peculiar seismicity, which can be considered as being unique in the world. A very small mantle volume of $30 \times 70 \times 130 \mathrm{~km}$ hosts earthquakes that occur repeatedly with magnitudes in excess of 7.5. Their frequency of occurrence and the level of ground motion they cause in the epicentral area and in Romania's capital Bucharest pose a geologic hazard to Romania and adjacent countries that is comparable to the hazard the recently devastated area of Izmit in Turkey (17 August 1999, Moment magnitude of 7.6) is exposed to.

Whereas the North Anatolian Fault has been thoroughly studied and strain and stress evolution are well understood a similar statement cannot be made for the Vrancea seismicity. In hazard assessment the definition of the source area or source volume by seismotectonic reasons is a critical step so that the understanding of the geodynamics responsible for those earthquakes is more than an academic exercise.

New efforts to decipher the tectonic history that formed the Carpathian Arc were launched within EUROPROBE's subproject PANCARDI. EUROPROBE is an international program of the European Science Foundation aiming to stimu-

Correspondence to: F. Wenzel

(friedemann.wenzel@gpi.uni-karlsruhe.de) late and support joint research between Eastern and Western scientists. PANCARDI focuses regionally on the PANnonian, CARpathian, and DInaridic geological evolution. With regard to the SE-Carpathians a new understanding evolved in recent years on the basis of new data and new concepts (see for instance Maţenco et al., 1997; Linzer et al.,1998; Gǐrbacea and Frisch, 1998; Sperner et al., 1999a, b).

In this paper we try to explain the Vrancea seismicity as result of a plate break-off process that occurs currently beneath Vrancea. We provide evidence that this hypothesis is in full agreement with the geological data available for the reconstruction of the Miocene plate interactions, with the pattern of seismicity and the related stress and strain fields in the upper mantle, and with recently derived upper mantle images by tomographic inversion of local and regional seismic data.

\section{The seismicity of the Vrancea area}

The seismicity of the Vrancea region in the SE-Carpathians is characterised by the occurrence of intermediate-depth earthquakes in a narrow epicentral and hypocentral region. Fig. 1 shows the distribution of crustal and intermediatedepth seismicity for events with magnitudes larger than 3.0 for the last two centuries according to Oncescu et al. (1998). Crustal seismicity is wide-spread over the area and - with two notable exceptions - does not exceed a magnitude of 5.5. The instrumentally well-located intermediate-depth seismicity is even more localised than indicated in Fig. 1. The epicentres are confined to a region of $30 \times 70 \mathrm{~km}$, with an average epicentral distance to Bucharest of about $130 \mathrm{~km}$. Earthquakes occur between 70 and $200 \mathrm{~km}$ depth within an almost vertical column. Deeper and shallower events have been recorded but only with small magnitudes. This source volume is the locus of the strong seismicity that dominates the earthquake hazard for Romania and adjacent countries. 


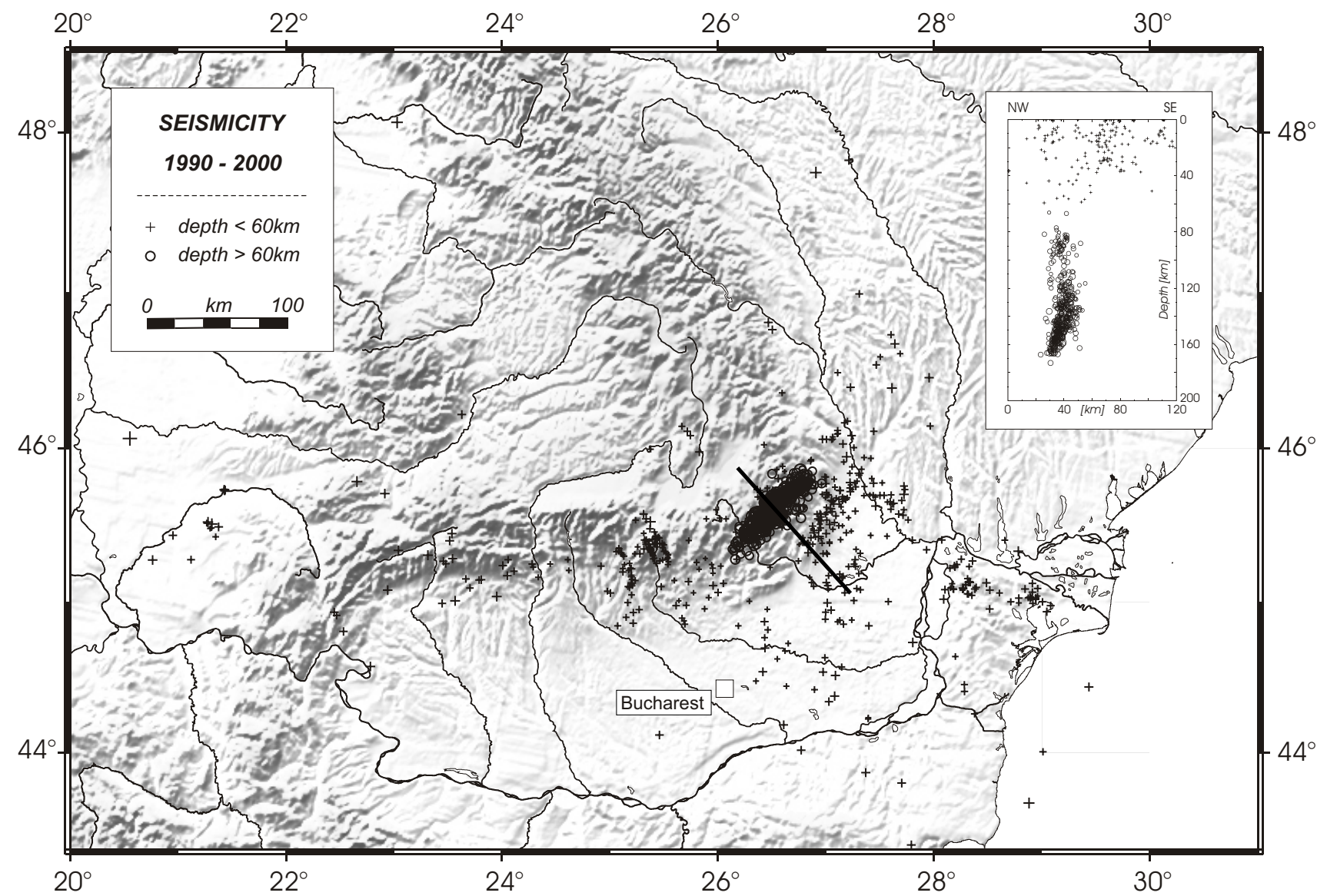

Fig. 1. Seismicity of the SE-Carpathians and surrounding regions during the last two centuries. Note that the main source of earthquake hazard, the intermediate-depth events, are clustered in a small area.

Within the last 60 years Romania has experienced four strong Vrancea earthquakes (Oncescu and Bonjer, 1997): 10 Nov. $1940\left(\mathrm{M}_{w}=7.7,160 \mathrm{~km}\right.$ deep$)$; 4 March $1977\left(\mathrm{M}_{w}=\right.$ 7.5, $100 \mathrm{~km}$ deep); 30 Aug. $1986\left(\mathrm{M}_{w}=7.2,140 \mathrm{~km}\right.$ deep); 30 May $1990\left(\mathrm{M}_{w}=6.9,80 \mathrm{~km}\right.$ deep $)$. The 1977 event had catastrophic character with 35 high-rise buildings collapsed and 1500 people killed, the majority of them in Bucharest.

All events at intermediate depth occur in a compressive, thrust faulting regime. The fault plane solutions of the instrumentally recorded large earthquakes are remarkably similar. They typically strike SW-NE $\left(\sim 220^{\circ}\right)$ and dip $60^{\circ}$ to $70^{\circ}$ to the NW. The slip angle is roughly $90^{\circ}$ (i.e. down dip). The similarity of the fault plane solutions contrasts strongly with significant variations of the radiation patterns which reflect the dynamics of the rupture process. The frequency of Vrancea events can be assessed from available catalogues. Earthquakes with Richter magnitudes in excess of 6.0 taken from Radu's (1991) compilation covering this century and transformed to moment magnitudes with Oncescu's (1987) relation satisfy a Gutenberg/Richter law (Lungu and Coman, 1994):

$\log _{10} N=4.1-0.78 M_{w}$ with $N$ as the number of events per year with magnitudes larger or equal to $\mathrm{M}_{w}$.

This provides recurrence times of 10 years for $\mathrm{M}_{w}>6.5$, 25 years for $\mathbf{M}_{w}>7.0$ and 50 years for $\mathbf{M}_{w}>7.4$. Historical data have been compiled by Radu (1974) and Purcaru (1979). Assuming that the data are complete for large magnitudes for the last 600 years, this time interval shows three earthquakes/century with $\mathrm{M}_{w}>7.2$ and six events/century with $\mathrm{M}_{w}>6.8$ in good agreement with the result based on relation (1).

\section{Plate tectonics and kinematics around the Vrancea area}

Sperner et al. (2001) and Wortel and Spakman (2000) provide evidence that the Miocene geodynamics of the Carpathians are controlled by a subduction process. During Miocene subduction the two intra-Carpathian blocks moved independently with different directions and velocities, only confined by the geometry of the continental embayment into which they moved and which was bordered by the European continent in the north and the east, and the Moesian platform in the south (Fig. 2; e.g. Csontos, 1998; Sperner et al., 1999a, b). 


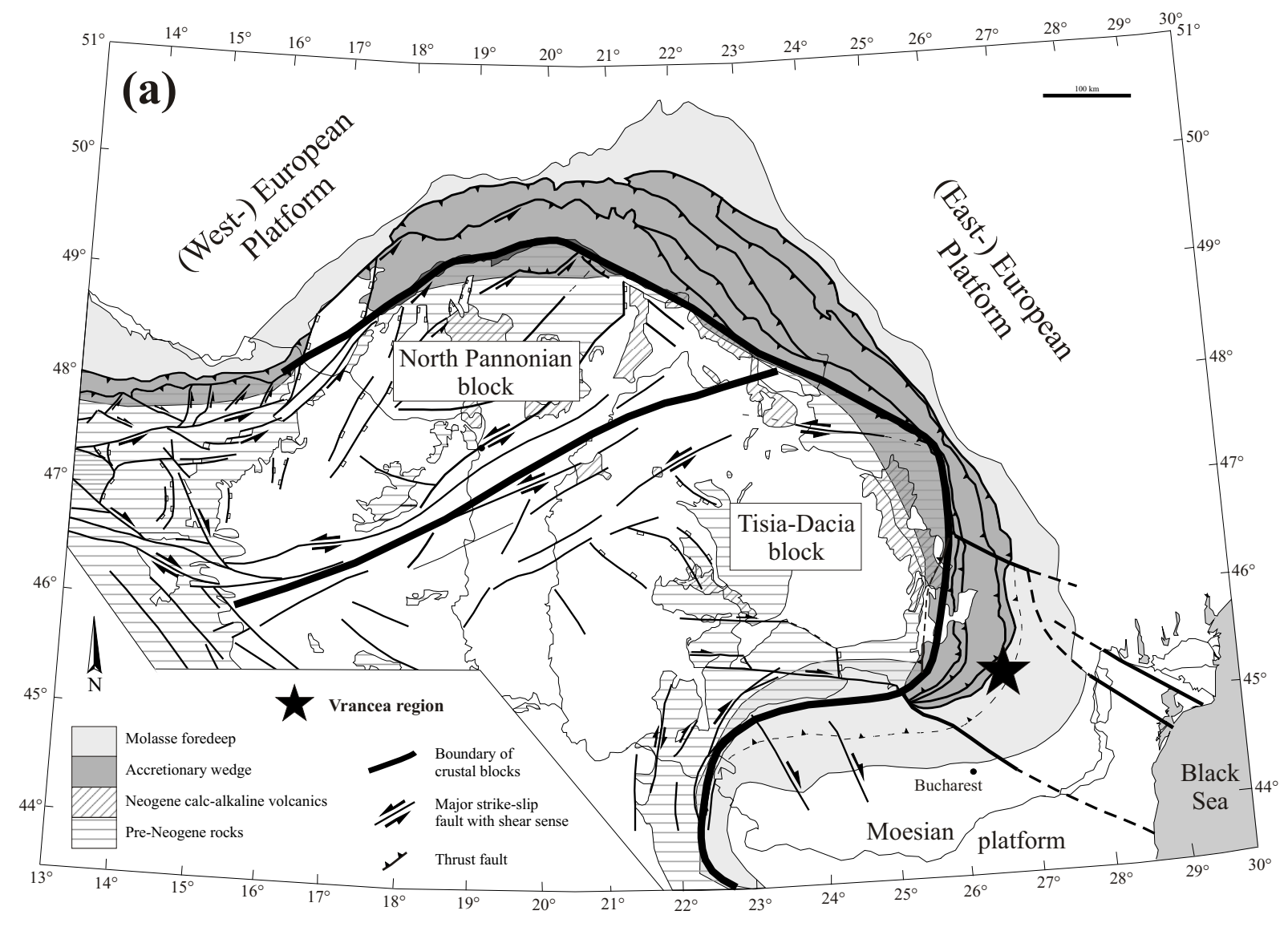

Ottnangian-Karpatian (16-17 Ma)
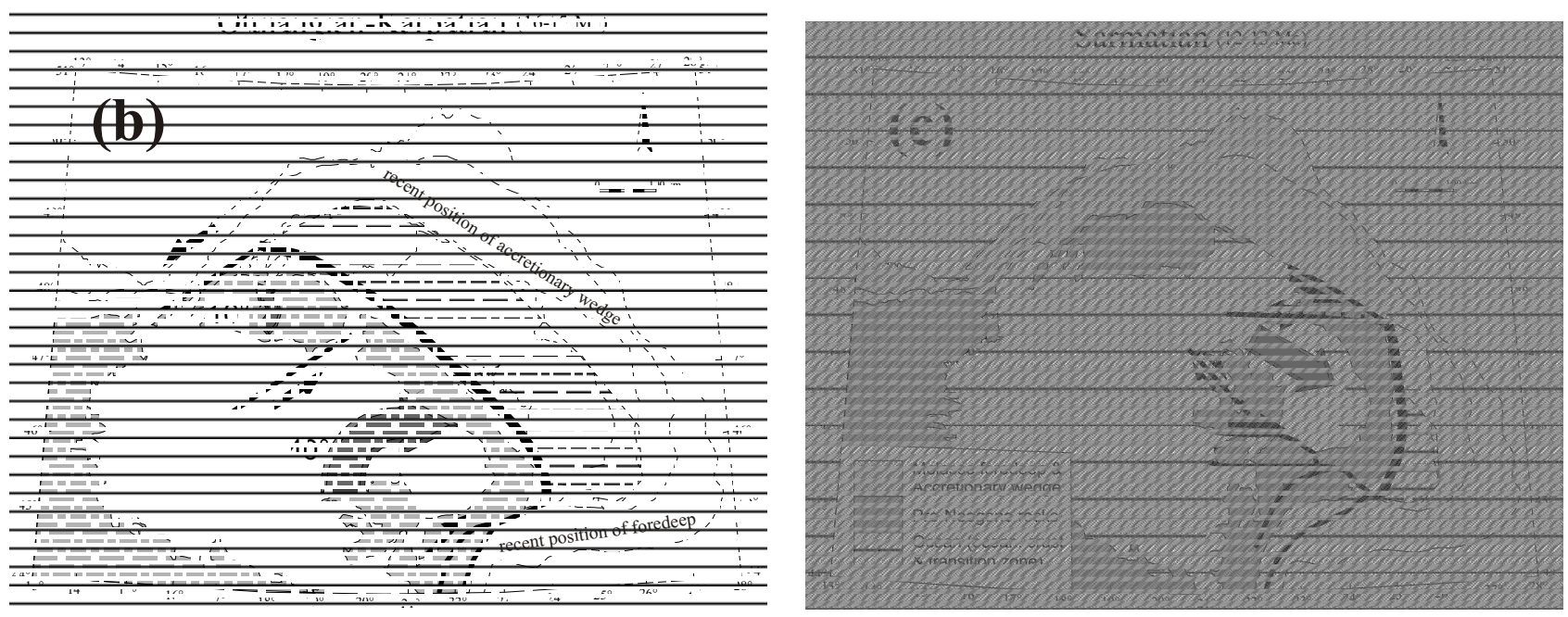

Fig. 2. Tectonics of the Carpatho-Pannonian region showing Tertiary-Quaternary structures and the epicentral area of the intermediatedepth earthquakes in the southeastern Carpathians (Vrancea region), (a) and geodynamic evolution of the Carpatho-Pannonian region during Miocene (after Sperner et al., 1999a). Opposite rotation of two crustal blocks (b) resulted in an oblique collision with the European foreland which started in the north and successively propagated towards the southeast and south (c).

Rotations of the blocks are proved by paleomagnetic data that reveal a $40^{\circ}$ counterclockwise rotation of the North Pannonian block (Márton and Fodor, 1995) and $60^{\circ}$ clockwise rotation of the Tisia-Dacia block (TDB) since the beginning of Miocene (Pătraşcu et al., 1994).
An accretionary wedge evolved during subduction at the frontal parts of the intra-Carpathian blocks. Oblique collision of the TDB with the European foreland resulted in differing post-collisional deformation styles in the northern and southern part of this fold-and-thrust belt. Overthrusting of 
the northeastern edge of the TDB onto the foreland led to shortening and crustal thickening in this part of the collision zone (Zweigel et al., 1998). Simultaneously, thinned continental crust was still available in the southern part, i.e. in the corner between Moesian platform and European continent, thus enabling gravitational collapse and basin formation in this part of the accretionary wedge. Basin formation in the accretionary wedge was additionally supported by delamination of the lower lithosphere followed by asthenospheric rise and surface uplift of this area (Gǐrbacea and Frisch, 1998).

Deformation structures at the southern border of the TDB are characterised as follows. Dextral strike-slip movements dominated the Miocene deformation along the contact between TDB and Moesian platform. Timing of this deformation comes from the subsidence of sedimentary basins caused by bendings and offsets along the main strike-slip faults (Moser and Frisch, 1996). Later on, basin inversion and thrusting onto the northern margin of the Moesian platform demonstrate the transpressive character of this strikeslip zone (Linzer et al., 1998). Foredeep basins evolved around the Carpathian arc, but a special situation is given in its southeastern corner where about $9 \mathrm{~km}$ of sediments were deposited during middle Miocene to Pleistocene time. Additionally, this region is characterised by strong subcrustal seismicity indicating the presence of a remnant of the subducted slab. Surprisingly, this slab is located $80-100 \mathrm{~km} \mathrm{SE}$ of the Miocene suture zone - an indication for delamination and rollback of the lower lithosphere (Gřrbacea and Frisch, 1998).

These findings are fully compatible with the evolution of a plate break-off process (Wortel and Spakman, 1993). Continental collision with following slab break-off occurred first in the northernmost part of the arc and later on shifted towards the SE and S leading to a corresponding shift of foreland basin depocenters and of volcanic activity (Sperner, 1996; Meulenkamp et al., 1997).

Large uplift rates are reported from the northern part of the Eastern Carpathians (Joó, 1985; Radulescu et al., 1996) where the TDB overthrusted the European foreland and thus caused crustal thickening. Smaller, but still remarkable uplift rates occur in the southern part where no crustal thickening took place, so that additional processes have to be considered. Slab break-off that started in the $\mathrm{N}$ and migrated towards the $\mathrm{S}$ can serve as such an additional mechanism.

\section{Upper mantle tomographic images}

Several tomographic studies of the Vrancea zone have been conducted. Spakman et al. (1993) derived an image of the entire Mediterranean area including SE-Europe. This image reveals such important features as the phenomenon of slab detachment in the Tyrrhenian Sea (Wortel and Spakman, 1992). Weak indications of slab detachment are also visible for the Carpathian arc. As standard ISC stations and data are used, the resolution of local features remains limited. Oncescu et al. (1984) inverted teleseismic events recorded by the Roma- nian earthquake network. A low-velocity structure could be identified between 40 and $80 \mathrm{~km}$ depth. The results of simultaneous inversion of hypocentres and P-wave velocities (Oncescu, 1984; Koch, 1985) indicate high-velocity material between 80 and $160 \mathrm{~km}$ depth, the level where intermediatedepth seismicity is located. A recent attempt by Fan et al. (1998) with a larger set of regional earthquakes and records confirms that the intermediate-depth seismogenic volume is characterised by high velocities.

Lorenz et al. $(1997,2001)$ restricted the input data used for inversion of teleseismic tomography to those stations of the Romanian network with digital recording. The digitally recorded waveforms for 125 events were picked, travel-time residuals were calculated with the IASP91 reference tables (Kennett, 1991) and the inversion was performed with the ACH-method (Aki et al., 1977). The weighted relative residual, which are more or less independent of hypocenter localisation errors, were minimised using a standard least squares algorithm (Aki and Richards, 1980). The best fit model implies a variance improvement of $70 \%$. Thus although the number of stations have been reduced as compared to Oncescu et al. (1984) the results are more significant due to the improved data quality.

Figure 3 shows depth levels of 74 to $112 \mathrm{~km}$ (Fig. 3a), 112 to $152 \mathrm{~km}$ (Fig. 3b), and 152 to $194 \mathrm{~km}$ (Fig. 3c). Each panel contains the sites of digital stations as triangles. The hypocentres of small earthquakes as observed during 1980 and 1994 are marked as dots and the sites of the large events between 1940 and 1990 as crosses. Both the pattern of stations and the azimuthal distribution of teleseismic earthquakes limit the volume that is illuminated by seismic rays and the resolution of the inversion. The resolution of the images is about 30 to 40 laterally at a depth range between 60 and $250 \mathrm{~km}$. The significant variance reduction mentioned before indicates that within these limits the highvelocity body found beneath Vrancea is real despite of the uneven station and source distribution. The latter conclusion is supported by the fact that other referenced tomographic images (with much lower resolution though) also show an isolated high-velocity body. The improved resolution we achieve allows a better correlation with hypocentres of strong and moderate intermediate-depth seismicity. With these constraints in mind we consider the following features as significant:

The images show blocks of low velocities $(-4 \%)$, which surround an area of higher velocity $(+4 \%)$ The high velocities extend from a subcrustal depth of $40 \mathrm{~km}$ all the way down to the maximum depth of $236 \mathrm{~km}$ mapped during inversion. The recent inversion of local events (Fan et al., 1998) shows results consistent with this observation. At intermediate-depth the elevated velocities appear only beneath Vrancea.

All intermediate-depth earthquakes are contained in the high-velocity volume beneath Vrancea. It appears that the seismogenic volume is smaller as compared to the highvelocity volume. Specifically the "cold" material extends to larger depth than the $200 \mathrm{~km}$ level marked by the deepest 
(a)

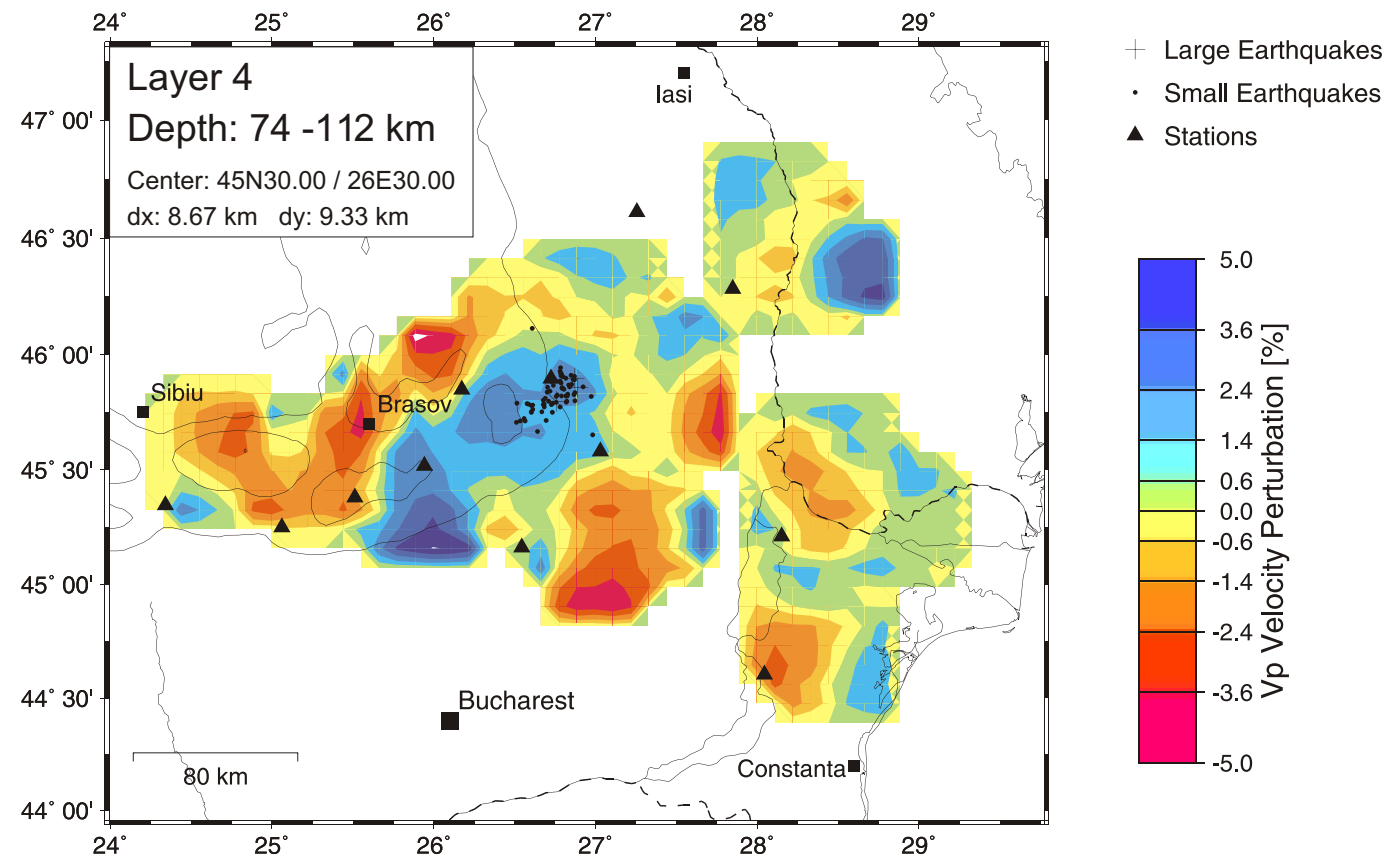

(b)

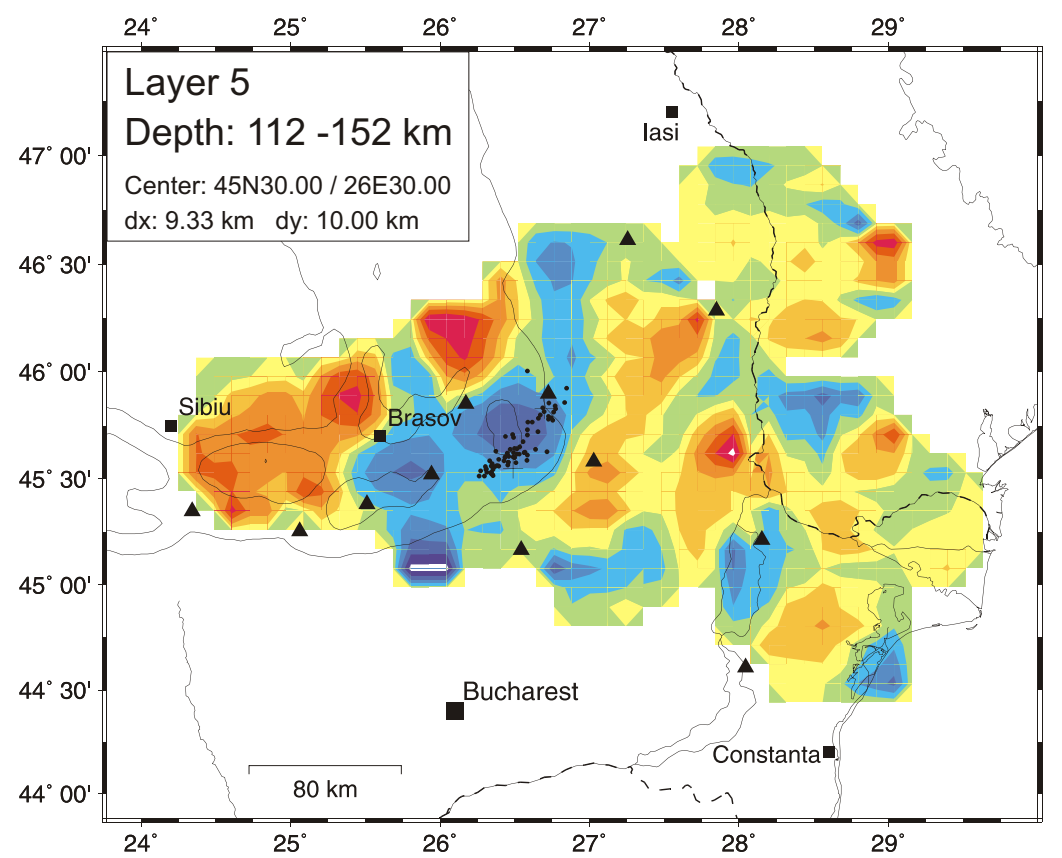

Fig. 3. Horizontal slices of upper mantle between $74 \mathrm{~km}$ and $194 \mathrm{~km}$ depth of the Vrancea area as derived from tomographic inversion of digital data from the Romanian telemetric network. (a) represents the depth range from 74 to $112 \mathrm{~km}$, (b) from 112 to $152 \mathrm{~km}$, (c) from 152 to $194 \mathrm{~km}$. Velocities vary from $-4 \%$ to $+4 \%$ as compared to the background model (Lorenz, 2000). Note that all recorded seismicity (dots and crosses) is confined to the high-velocity areas. (Fig. 3 continues ...

earthquakes. The earthquakes occupy a small strip within the high-velocity body that tends from the NE at a level around $90 \mathrm{~km}$ (Fig. 3a) to the SW at the level where the deepest earthquakes are observed. It is also noteworthy that no specific velocity structure within the limits of resolution characterises the depth level of very low seismicity ( 40 to $70 \mathrm{~km}$ ) and the depths below the deepest events. On a global scale all images of active subduction zones are characterised by positive $\mathrm{P}$-wave velocity anomalies. We take this as strong evidence for the presence of a slab of subducted lithosphere beneath Vrancea.

The volume of elevated velocities displays a peculiar structure, the main feature of which is a change of strike from top to bottom. The uppermost high-velocity material has a 
(c)

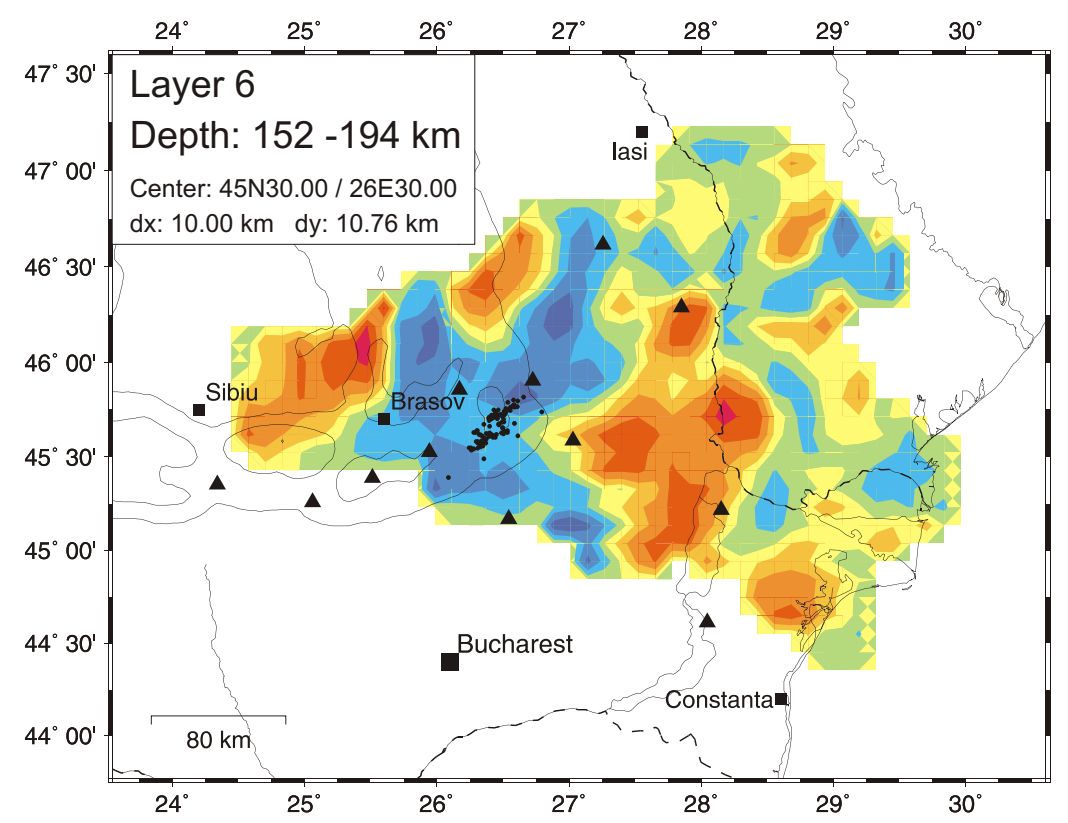

Fig. 3. ... continued.

strike orientation roughly SW-NE. This is consistent with a NW-ward subduction. The deeper portions of the highvelocity material, however, are oriented S-N. This orientation is close to the current strike of the Eastern Carpathians. Presumably this is also the strike of the subduction zone before the last segment of lithosphere - the Vrancea segment - was incorporated into the mantle. Thus the directional change of subduction during the last phases of collision in the Eastern Carpathians is preserved in the tomographic image. The S$\mathrm{N}$ oriented high-velocity material represents older $\mathrm{W}$-ward subducted material that is detached from the foreland lithosphere but still attached to the SW-NE trending Vrancea slab. The additional portion of heavy oceanic lithosphere generates a pull-down force which increases the shear stresses in this passive slab.

\section{Strain and stress beneath Vrancea}

An estimation of the seismic moment release rate $\left(\mathrm{M}_{o}\right)$ is a useful quantity to compare the level of seismic activity between different seismotectonic areas. The Gutenberg/Richter relation (1) and an assumed maximum possible magnitude of $\mathbf{M}_{w}=8.0$ result in $\mathbf{M}_{o}=0.8 \times 10^{19} \mathrm{Nm} / \mathrm{yr}$. This represents the average amount of seismic moment released per year by Vrancea earthquakes and is proportional to the elastic energy release rate. Almost the same result is achieved if we add the seismic moments of the four last strong events $(1940,1977$, 1986, 1990) which according to Oncescu and Bonjer (1997) amount to $0.75 \times 10^{21} \mathrm{Nm}$ and divide it by a period of 100 years.

Table 1 compares the moment release rate of Vrancea with those of several active plate boundary regions (Jackson and
Table 1. Comparison of moment release rates for various tectonic active areas of the Mediterranean and the Middle East (after Jackson and McKenzie, 1988; Ward, 1994)

\begin{tabular}{lc}
\hline Region & $\mathrm{M}_{o}$ in $10^{19} \mathrm{Nm} / \mathrm{yr}$ \\
\hline Aegean & 2.5 \\
N-Anatolian Fault & 2.3 \\
Kopet Dag & 1.5 \\
Southern California & 0.8 \\
Vrancea & $\mathbf{0 . 8}$ \\
Zagros & 0.4 \\
Caucasus & 0.3 \\
\hline
\end{tabular}

McKenzie, 1988; Ward, 1994). The moment release rates of the Aegean and N-Anatolian Fault region exceed the Vrancea value by a factor of 3 . However, the latter is comparable to Southern California and twice as high as values of the Zagros mountains and the Caucasus (Table 1).

Moment release rates can be cast in terms of strain rates with Kostrov's (1974) relation between moment and strain tensors. Taking the moment tensors of the last four large Vrancea earthquakes (Oncescu and Bonjer, 1997), a source volume of $2.5 \times 10^{5} \mathrm{~km}^{3}(70 \times 30 \times 130 \mathrm{~km}$ defined by the instrumentally observed seismicity) and a mantle shear modulus of $7.5 \times 10^{10} \mathrm{~Pa}$ gives a strain rate of $\dot{\varepsilon}=2 \times 10^{-7} \mathrm{yr}^{-1}$ or $6.3 \times 10^{-15} \mathrm{sec}^{-1}$. With this strain rate the source volume is stretched in the vertical direction and shortened in horizontal direction. Again this strain rate compares well with 
values from active plate boundaries such as Southern California where a similar amount of strain is observed by geodetic means (Ward, 1994, Fig. 3). We elaborate this point in order to show that Vrancea seismicity, given its seismic moment release and associated strain rates, is of plate boundary scale. The estimated strain rate deforms a vertical slab with $130 \mathrm{~km}$ length by $2.6 \mathrm{~cm} / \mathrm{yr}$ in vertical direction. If this strain rate, based on a hundred years of instrumental observation and compatible with 600 years of historic seismicity is extrapolated to geological times a value of $26 \mathrm{~km}$ vertical elongation in one million years is expected.

Geological evidence suggests that active subduction beneath the Eastern Carpathians ceased about 10 million years ago. When subduction comes to a halt the suction force responsible for the dip-angle of the subducting plate (Turcotte and Schubert, 1982) becomes zero and the plate exposed to nothing but gravitational forces will steepen towards a vertical position. The steepening might occur even during active subduction as soon as the slab becomes segmented (Dvorkin et al., 1993). For a first order understanding of the stress field within a slab exposed to gravity and buoyancy only we estimate the stress field within a rectangular block of highdensity material $\left(\rho_{s}\right)$, attached to a rigid layer underlain by a low-density $\left(\rho_{m}\right)$ mantle. The horizontal stress $\left(\sigma_{h}\right)$ equals the lithostatic pressure of the surrounding mantle, whereas the vertical stress $\left(\sigma_{v}\right)$ equals the lithostatic pressure within the slab reduced by the buoyancy effect:

$\sigma_{n}=\rho_{m} \cdot g \cdot z$

$\sigma_{v}=\rho_{s} \cdot g \cdot z-\left(\rho_{s}-\rho_{m}\right) \cdot g \cdot L$

with a total slab length L, gravitational acceleration $g$ and depth $\mathrm{z}$.

Within the slab the stress field changes from tensile at shallow depth $\mathrm{z}<\mathrm{L} \times\left(\rho_{s}-\rho_{m}\right) / \rho_{s}$ to compressive at deeper levels. As this model is rather crude for shallow levels we focus on those depths that are relevant to intermediate-depth seismicity. With $\rho_{m}=3200 \mathrm{~kg} / \mathrm{m}^{3}, \rho_{s}=3400 \mathrm{~kg} / \mathrm{m}^{3}, \mathrm{~g}=$ $10 \mathrm{~m} / \mathrm{s}^{2}$ and $\mathrm{L}=200 \mathrm{~km}$ the stresses are compressive below $12 \mathrm{~km}$ depth. The buoyancy effect amounts to $0.4 \mathrm{GPa}$, so that the maximum differential stress decreases from $0.4 \mathrm{GPa}$ to zero at the lower end of the slab where lithostatic conditions prevail. Thus this simple model is consistent with the stress field suggested by the fault plane solutions. However, the maximum possible shear stress remains on a fairly low level at the seismogenic depths between 70 (260 MPa) and $200 \mathrm{~km}$ (no shear stress).

However, the tomographic images discussed previously indicate that the high-velocity (and there high-density) volume extends significantly beneath $200 \mathrm{~km}$ depth (Lorenz et al., 1997; Fan et al., 1998). Thus the seismogenic volume differs from the high-density volume such that there are parts of the slab that extend below the deepest level of seismicity. With an additional $150 \mathrm{~km}$ of aseismic slab the level of maximum possible shear stress exceeds $300 \mathrm{MPa}$ everywhere within the seismogenic volume. Although the frictional strength of rocks under very high confining pressure $(5$
GPa) are not known, estimates of lithosphere strength using plate bending geometry indicate that this level of shear stress may be sufficient to rupture oceanic lithosphere (Goetze and Evans, 1979). Thus the simple model demonstrates (a) that a thrust faulting regime within the slab should prevail and (b) that a deep aseismic part of the high-density material is required (200 to $350 \mathrm{~km}$ depth) to generate seismicity down to $200 \mathrm{~km}$.

\section{Discussion}

The geodynamic model synthesises interpretations of plate kinematics, the findings of seismic tomography and the peculiarities of the stress and strain fields in the upper mantle as documented by seismicity.

It assumes that Miocene subduction beneath the Carpathians was characterised by rollback of the subducting slab leading to a northeast and eastward movement of the intraCarpathian blocks accompanied by counterrotation of these blocks (Fig. 2; Royden, 1988). Slab steepening produced along-strike extension, whereas the curved geometry of the Carpathian Arc led to a segmentation of the slab (Sperner, 1996). The middle Miocene continental collision in the northern part of the Carpathians blocked the subduction and plate break-off of the slab segments started (Fig. 4).

In the southeastern bend of the Carpathians where collision occurred most recently, the slab segment is still partly attached to the overlying crust. Two pre-existing, crustalscale fault zones, which originate from older collisions between the European foreland and two crustal blocks (Dobrogea block and Moesian block) both strike NW-SE (Fig. 2). They represent (lithospheric) heterogeneities between which delamination of the lower lithosphere took place after continental collision. It led to a southeastern shift of the subducted slab and to asthenospheric upwelling beneath the collision zone (Grirbacea and Frisch, 1998).

The combination of surface (geological) and subsurface (geophysical) data resulted in a geodynamic model of the Carpathians that integrates both the Neogene movements of the intra-Carpathians blocks with respect to the European foreland as well as mantle processes active during subduction and collision. Together they define the boundary conditions for a realistic seismic hazard assessment. They give constraints on the location and size of the potential seismogenic volume and enable the identification of possible earthquake failure mechanisms.

The precise location and size of the high-velocity body beneath Vrancea that hosts all intermediate-depth seismicity is critical with respect to three features.

The lateral extent of the high-velocity body should constrain the minimum distance the hypocentre can have with respect to the Romanian capital Bucharest. For instance, with the attenuation relation given by Lungu and Coman (1994), the horizontal peak ground acceleration (PGA) for an earthquake of moment magnitude 7.5 with hypocentre at $100 \mathrm{~km}$ depth changes from $200 \mathrm{~cm} / \mathrm{s}^{2}$ to $250 \mathrm{~cm} / \mathrm{s}^{2}$ if the hypocentre 


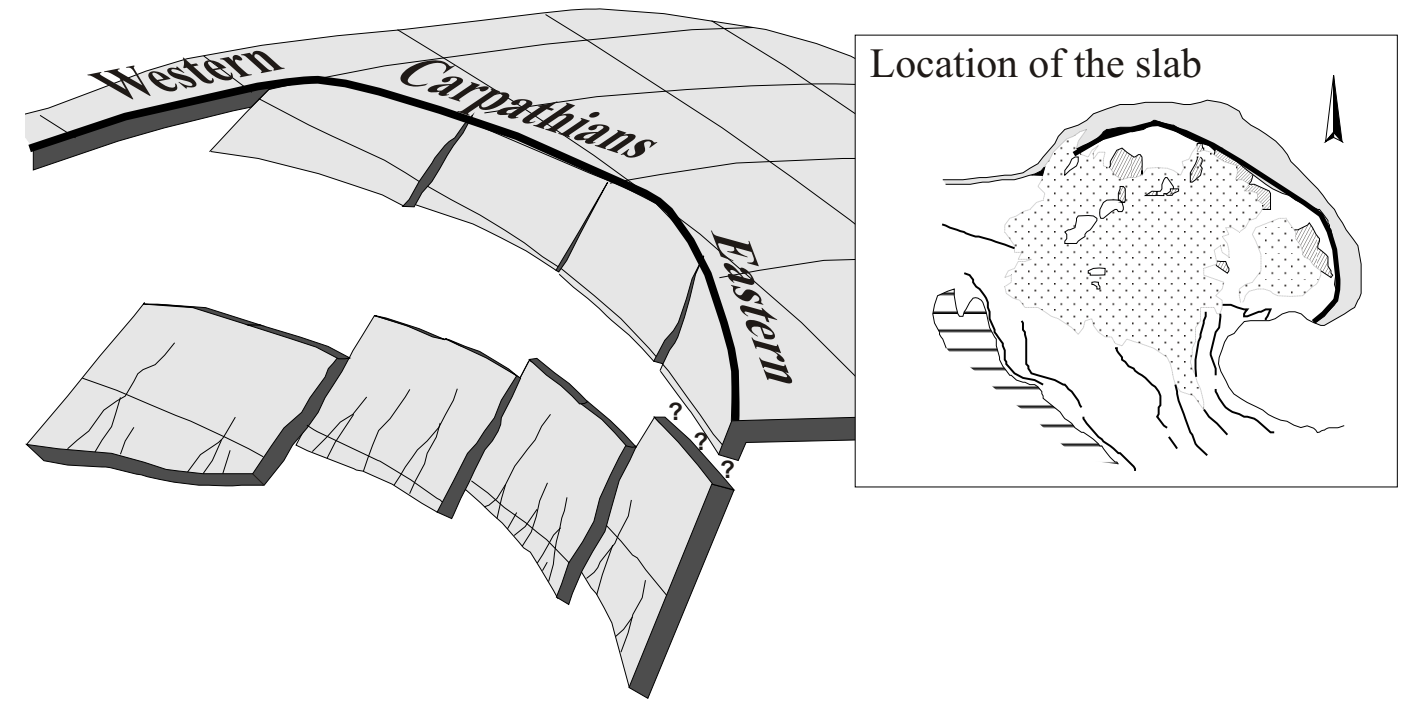

Fig. 4. Model for plate break-off beneath the Carpathian arc (after Sperner, 1996). The slab segments in the northern parts are already detached, the southernmost segment is still mechanically coupled to the European plate.

is moved $40 \mathrm{~km}$ closer to Bucharest. If high-resolution tomography rules out such a close distance an important constraint on hazard estimates is established.

The structure of the upper mantle between the Moho and the seismogenic zone is of utmost importance for seismic hazard. The current assumption is that hypocentres of strong earthquakes should not be shallower than $70 \mathrm{~km}$ depth. Moving this depth to a shallower level will significantly increase the ground motion in the epicentral area. Using the same attenuation relation for a magnitude 7.0 event at $80 \mathrm{~km}$ depth and at $60 \mathrm{~km}$ depth results in an increase of PGA from $300 \mathrm{~cm} / \mathrm{s}^{2}$ to $480 \mathrm{~cm} / \mathrm{s}^{2}$ for the epicentral area.

The lateral extent of the high-velocity body provides a constraint on the maximum earthquake possible because it has to accommodate the entire rupture area. Estimates of the rupture area (A) from previous large Vrancea events (Oncescu and Bonjer, 1997) confirm that Wells and Coppersmith's (1994) relation $M=4.07+\log _{10} \mathrm{~A}$ is applicable. Assuming a 1:2 relation of horizontal length to vertical width of the rupture area an event of moment magnitude of 7.5 would fit into a high-velocity body with $80 \mathrm{~km}$ SW-NE extension. If the body extends $100 \mathrm{~km}$ instead the maximum magnitude becomes 7.7. Thus a tomographic resolution of $20 \mathrm{~km}$ suffices to constrain the maximum magnitude to 0.2 magnitude units.

For these reasons high-resolution tomography as carried out in 1999 with 130 mobile instruments (Wenzel et al., 1998) will prove very valuable not only for revealing the mantle dynamics of the area but also for hazard assessment.

\section{Conclusions}

A synthesis of geological data, the results of seismic tomography, and features of the intermediate-depth seismicity is consistent with a geodynamic model in which the last stage of a plate break-off process occurs currently beneath the SECarpathian Vrancea area. The geological data constrain the collision/subduction process and the associated kinematics of the involved plates. Tomography maps a high-velocity body at depth that contains all instrumentally recorded seismicity. Its positive velocity contrast is indicative of cold remnant oceanic lithosphere. Its geometry reflects the varying directions of the subduction process. The seismicity reveals the stress field in the mantle and indicates that the remnant slab is pulled downwards. The deformation rate of this process is in the order of $10^{-2} \mathrm{~m}$ per year and thus on the scale of active plate boundary phenomena.

High deformation rates, as reflected in seismicity, limited to a depth interval of 70 to $200 \mathrm{~km}$ suggest that this depth level represents an area of stress concentration. The tomographic images show that there is more cold material beneath $200 \mathrm{~km}$. The (former) Carpathian subduction zone is no longer an active Benioff-Wadati zone but rather a passively sinking almost detached slab. Although the area of high seismicity naturally coincides with high deformation rates this does not necessitate this depth as the actual breakoff zone. The latter could be the aseismic depth level between brittle upper crust and $70 \mathrm{~km}$ depth.

One intriguing question related to Vrancea earthquakes is: why is this type of seismicity rarely observed on Earth? Our geodynamic model suggests that the terminal phase of slab break-off spans a geologically brief interval. Extreme localisation of vertical lithospheric deformation and associated seismicity may last for only a few million years and therefore represents a rare event. Thus the area around Vrancea may provide insight into a common, but short-lived process that can be observed and understood only at one spot on Earth today. 
Acknowledgements. This work was accomplished with funds of the Collaborative Research Center "Strong Earthquakes" (CRC 461). The CRC has been established in 1996 and is supported by the Deutsche Forschungsgemeinschaft (DFG), the State of BadenWuerttemberg, and the University of Karlsruhe. We would like to thank for two very constructive reviews that helped to improve the manuscript.

\section{References}

Aki, K., Christoffersson, A., and Husebye, E. S.: Determination of the three-dimensional seismic structure of the lithosphere, J. Geophys. Res., 82, 277-296, 1977.

Aki, K. and Richards, P. G.: Quantitative seismology: theory and methods, Elsevier, Amterdam, 1980.

Csontos, L.: Tertiary tectonic evolution of the Intra-Carpathian area: a review, Acta Vulc., 7, 2, 1-13, 1998.

Dvorkin, J., Nur, A., Mavko, G., and Ben Avraham, Z.: Narrow subducting slabs and the origin of backarc basins, Tectonophysics, 227, 1-4, 63-79, 1993.

Fan, G., Wallace, T. C., and Zhao, D.: Tomographic imaging of deep velocity structure beneath the Eastern and Southern Carpathians, Romania: implications for continental collision, J. Geophys. Res. 103 (B2), 2701-2723, 1998.

Gřrbacea, R. and Frisch, W.: Slab in the wrong place: Lower lithospheric mantle delamination in the last stage of the Eastern Carpathian subduction retreat, Geology, 26, 7, 611-614, 1998.

Goetze, Ch. and Evans, B.: Stress and temperature in the bending lithosphere as constrained by experimental rock mechanics, Geophys. J.R. astr. Soc. 59, 463-478, 1979.

Jackson, J. and McKenzie, D.: The relationship between plate motion and seismic moment tensors, and the rates of active deformation in the Mediterranean and Middle East, Geophysical Journal, 93, 45-73, 1988.

Joó, I. (Ed.): Map of recent vertical movements in the CarpathoBalkan region, 1:1 000 000, National Office of Lands and Mapping, Budapest, 1985.

Kennett, B. L. N. (Ed.): IASPEI 1991 seismological tables, Canberra, $167 \mathrm{pp}, 1991$.

Koch, M.: Nonlinear inversion of local seismic travel times for the simultaneous determination of the 3D-velocity structure and hypocentres - application to the seismic zone Vrancea, J. Geophys., 56, 160-173, 1985.

Kostrov, V.: Seismic moment and energy of earthquakes, and seismic flow of rocks, Izv. Acad. Sci. USSR, Phys. Solid Earth, 1, 23-44, 1974.

Linzer, H.-G., Frisch, W., Zweigel, P., Gřrbacea, R., Hann, H.-P., and Moser, F.: Kinematic evolution of the Romanian Carpathians, Tectonophysics, 297, 1-2, 133-156, 1998.

Lorenz, F. P.: Optimierung mehrdimensionaler Inversionsrechnungen zur Anpassung von Laufzeiten elastischer Wellen, Dissertation, Universität Karlsruhe, 2000.

Lorenz, F. P., Martin, M., Sperner, B., Wenzel, F., and Popa, M.: Teleseismic travel-time tomography of the compressionalwave velocity structure in the Vrancea zone, Romania, AGU Fall Meeting, San Francisco, USA, Dec., 8-12, 1997.

Lungu, A. and Coman, O.: Experience database of Romanian facilities subjected to the last three Vrancea earthquakes. Part I: Probabilistic hazard analysis to the Vrancea earthquakes in Romania, Research Report for the International Atomic Energy Agency, Vienna, Austria, Contract No. 8223/EN, 1994.
Márton, E. and Fodor, L.: Combination of palaeomagnetic and stress data - a case study from Northern Hungary, Tectonophysics, 242, 99-114, 1995.

Maţenco, L., Bertotti, G., Dinu, C., and Cloetingh, S. A. P. L.: Tertiary tectonic evolution of the external South Carpathians and the adjacent Moesian platform (Romania), Tectonics, 16, 3, 896911, 1997.

Meulenkamp, J. E., Kovác, M., and Cicha, I.: On Late Oligocene to Pliocene depocentre migrations and the evolution of the Carpathian-Pannonian system, Tectonophysics, 266, 1-4, 301318, 1997.

Moser, F. and Frisch, W.: Tertiary deformation in the Southern Carpathians - Structural analysis of a brittle deformation, TSK 6 Symposium, Salzburg, Austria, Abstract Volume, 280-282, 1996.

Oncescu, M. C.: Deep structure of Vrancea region, Romania, inferred from simultaneous inversion for hypocentres and 3-D velocity structure, Ann. Geophys., 2, 23-28, 1984.

Oncescu, M. C.: On the magnitude and depth recurrence of Vrancea earthquakes, Report ICEFIZ EP-34-1987 (in Romanian), 20 p, 1987.

Oncescu, M. C., Bulacu, V., Anghel, M., and Smalbergher, V.: Three-dimensional P-wave velocity image under the Carpathian Arc, Tectonophysics, 106, 305-319, 1984.

Oncescu, M. C. and Bonjer, K.-P.: A note on the depth recurrence and strain release of large Vrancea earthquakes, Tectonophysics, 272, 2-4, 291-302, 1997.

Oncescu, M. C., Marza, I. V., Rizescu, M., and Popa, M.: The Romanian earthquake catalogue between 1984-1996, in: Wenzel, F., Lungu, D., and Novak, O. (Eds.): Vrancea Earthquakes: Tectonics, Hazard and Risk Mitigation, 43-47, 1998.

Pătraşcu, St., Panaiotu, C., Seclaman, M., and Panaiotu, C. E.: Timing of rotational motion of Apuseni Mountains (Romania): paleomagnetic data from Tertiary magmatic rocks, Tectonophysics, 233, 163-176, 1994.

Purcaru, G.: The Vrancea, Romania, earthquake of March 4, 1977 a quite successful prediction, Phys. Earth Planet. Inter., 18, 274 287, 1979.

Radu, C.: Contribution l'étude de la séismicité de la Roumanie et comparaison avec la séismicité de sud-est de la France, Ph.D. thesis, Université de Strasbourg, 404 p, 1974.

Radu, C.: Strong earthquakes occurred on the Romanian territory in the period 1901-1990, Vitralii, 3, (in Romanian), 12-13, 1991.

Radulescu, F., Mocanu V., Nacu V., and Diaconescu, C.: Study of recent crustal movements in Romania; a review, Journal of Geodynamics, 22, 33-50, 1996.

Royden, L.: Late Cenozoic tectonics of the Pannonian basin system, Mem. Am. Ass. Petrol. Geol., 45, 27-48, 1988.

Spakman, W., van der Lee, S., and van der Hilst, R.: Traveltime tomography of the European-Mediterranean mantle down to $1400 \mathrm{~km}$, Phys. Earth Planet. Inter., 79, 3-14, 1993.

Sperner, B.: Computer programs for the kinematic analysis of brittle deformation structures and the Tertiary tectonic evolution of the Western Carpathians, Tübinger Geowiss. Arbeiten, A27, 120 p, 1996.

Sperner, B., Lorenz, F. P., Bonjer, K. P., Hettel, S., Müller, B., and Wenzel, F.: Slab break-off - abrupt cut or gradual detachment? New insights from the Vrancea Region (SE Carpathians, Romania), Terra Nova, 13 (3), 172-179, 2001.

Sperner, B., Ratschbacher, L., Zweigel, P., Moser, F., Hettel, S., Lorenz, F., Gǐrbacea, R., and Wenzel, F.: Lateral extrusion, slab break-off and subduction retreat: the Oligocene-Recent 
collision-subduction transition in the Alps and Carpathians, Penrose Conference: Subduction to Strike-Slip Transitions on Plate Boundaries, Puerto Plata, Domin. Rep., Jan., 18-24, 1999, 103104, 1999a. (available on-line at $\backslash$ http://www.uncwil.edu/people/ grindlayn/penrose.html)

Sperner, B., Moser, F., Zweigel, P., Gǐrbacea, R., and Ratschbacher, L.: The subduction to strike-slip transition in the SE Carpathians: structural, sedimentary, and surface uplift response to subduction retreat and slab break-off, Penrose Conference: Subduction to Strike-Slip Transitions on Plate Boundaries, Puerto Plata, Domin. Rep., Jan., 18-24, 1999, 105-106, 1999b. (available online at http://www.uncwil.edu/people/grindlayn/penrose.html)

Turcotte, D. L. and Schubert, G.: Geodynamics: Application of Continuum Physics to Geological Problems, John Wiley \& Sons, ISBN 0-471-06018-6, 1982.

Ward, S. N.: A multidisciplinary approach to seismic hazard in Southern California, Bull. Seismol. Soc. America, 84, 5, 12931309, 1994.

Wells, D. L. and Coppersmith, K. J.: New empirical relationships among magnitude, rupture length, rupture width, rupture area and surface displacement, Bull. Seismol. Soc America, 84, 4, 974-1002, 1994.

Wenzel, F., Achauer, U., Enescu, D., Kissling, E., Russo, R., Mocanu, V., and Musacchio, G.: Detailed look at final stage of plate break-off is target of study in Romania, EOS, 79, 48, 589-594, 1998.

Wortel, R. and Spakman, W.: Subduction and slab detachment in the Mediterranean-Carpathian region, Science, 290, 1910-1917, 2000.

Wortel, M. J. R. and Spakman, W.: Structure and dynamics of subducted lithosphere in the Mediterranean region, Proc. Kon. Ned. Akad. v. Wetensch., 95, 3, 325-347, 1992.

Wortel, M.J.R. and Spakman, W.: The dynamic evolution of the Apenninic-Calabrian, Hellenic, and Carpathian arcs: a unifying approach, Terra Nova, Abstr. suppl., 5, 1, 97, 1993.

Zweigel, P., Ratschbacher, L., and Frisch, W.: Kinematics of an arcuate fold-thrust belt: the southern Eastern Carpathians (Romania), Tectonophysics, 297, 1-4, 177-208, 1998. 